\title{
Predicting Weight Loss and Maintenance in Overweight/Obese Pediatric Patients
}

\author{
Susanna Wiegand ${ }^{a} \quad$ Klaus-Michael Keller $^{b}$ Thomas Lob-Corzilius ${ }^{c}$ \\ Wilfried Pott ${ }^{d}$ Thomas Reinehr ${ }^{\mathrm{e}}$ Markus Röbl $^{\mathrm{f}}$ Rainer Stachow ${ }^{\mathrm{g}}$ \\ Sabine Tuschy ${ }^{\mathrm{h}}$ Ingo Weidanz ${ }^{\mathrm{i}}$ Kurt Widhalm' Martina de Zwaan ${ }^{\mathrm{j}}$ \\ Reinhard W. Hollk
}

\begin{abstract}
a Department of Pediatric Endocrinology and Diabetology, Charité University Medicine, Berlin, bepartment of Pediatrics, German Clinic for Diagnostics, Wiesbaden, ${ }^{C}$ Christliches Kinderhospital Osnabrück GmbH, Zentrum für Kinder- und Jugendmedizin, Osnabrück, ${ }^{\mathrm{d} D R K}$ Kinderklinik Siegen, Siegen, e Department of Pediatric Endocrinology, Diabetes and Nutrition Medicine, Vestische Children's Hospital, University of Witten/Herdecke, Datteln, ${ }^{\text {f Social }}$ Pediatric Center, University of Göttingen, Göttingen, ${ }^{9}$ Rehabilitation Clinic Sylt, Westerland, ${ }^{h}$ Sozialpädiatrisches Zentrum-Übergewicht/Adipositas, Klinik für Kinder- und Jugendmedizin, Sana Klinikum Lichtenberg, Berlin, ${ }^{i}$ Clinic Bremen-Nord, Bremen, j'Department of Psychosomatic Medicine and Psychotherapy, Hannover Medical School, Hannover, and k'Department of Epidemiology, University of Ulm, Ulm, Germany; 'Division of Clinical Nutrition, Obesity and Lipid Disorders, Department of Pediatrics, Medical University of Vienna, Vienna, Austria
\end{abstract}

\section{Key Words}

Childhood obesity · Overweight · Weight pattern ·

Weight reduction - Weight maintenance

\begin{abstract}
Background: Pediatric lifestyle interventions have positive short-term effects on obese patients. Studies on long-term effects are still scarce in Europe. We investigated long-term weight patterns and sociodemographic predictors of a weight change in a large Central European (Germany, Austria and Switzerland) overweight pediatric cohort. Methods: The APV (Adiposity Patients Verlaufsbeobachtung) database was retrospectively analyzed; 157 specialized childhood obesity centers contributed standardized data of 29,181 patients [body mass index (BMI) $\geq 90$ th percentile; $5-25$ years old] presenting between 2000 and 2012. BMI standard de-
\end{abstract}

viation scores (BMI-SDS) were analyzed in a 2-year follow-up and grouped according to BMI-SDS changes. Multiple logistic regression analyses were conducted to assess associations between sociodemographic factors and weight patterns. Results: 2-year follow-up data were available in 3,135 patients $(54.6 \%$ female). Five distinct weight trajectories 'rapid weight loss' ( $\mathrm{n}=735,23.4 \%$ ), 'delayed success' ( $\mathrm{n}=$ 697, 22.2\%), 'cycling weight' ( $n=43,1.4 \%$ ), 'initial weight loss' and 'weight rebound' ( $\mathrm{n}=383,12.2 \%$ ) and 'no weight loss throughout' ( $n=1,277,40.7 \%$ ) best characterized longterm BMI-SDS changes. Younger and male patients were more likely to reduce weight and maintain weight loss. Conclusions: Our results suggest that an intervention before the onset of puberty seems promising for long-term weight maintenance in overweight children. Thus, new concepts are needed to improve long-term treatment success in patients with lower success rates.

(c) 2014 S. Karger AG, Basel

\section{KARGER}

E-Mail karger@karger.com

www.karger.com/hrp (c) 2014 S. Karger AG, Basel

$1663-2818 / 14 / 0826-0380 \$ 39.50 / 0$
Prof. Dr. med. Reinhard Holl

Institut für Epidemiologie und medizinische Biometrie/ZIBMT, Universität Ulm Albert-Einstein-Allee 41

DE-89081 Ulm (Germany)

E-Mail reinhard.holl@uni-ulm.de 


\section{Introduction}

Approximately $15 \%$ of children/adolescents living in Germany are overweight or obese [1]. This presents a tremendous public health concern since childhood obesity is linked to a range of cardiovascular and metabolic risk factors, such as hypertension, type 2 diabetes and hyperlipidemia [2]. In addition, it is a significant risk factor for adult obesity and more severe obesity in adulthood $[3,4]$. Weight loss is known to improve cardiovascular risk factors, and this benefit appears to persist as long as weight reduction is maintained [5]. Multidisciplinary and behavior-oriented lifestyle interventions constitute the cornerstone of therapy in pediatric obesity [6,7]. Several systematic reviews of the treatment of childhood obesity showed clinically meaningful effects of short-term lifestyle interventions [8-10]. As obesity is a chronic disease, maintenance of a stable weight after an initial weight loss constitutes a considerable challenge [11]. Interestingly, $10-20 \%$ of individuals successfully maintain a decreased body weight following a lifestyle intervention program $[12,13]$. Studies indicate that several biological factors, such as appetite-regulating hormones [14], demographic factors, such as age $[15,16]$, psychosocial factors, like maternal depression [17], treatment-response-related factors, such as change in body mass index (BMI) standard deviation scores (SDS) during the 1st year of intervention [15], and presence of familial obesity [17] may be predictive of long-term weight maintenance. Overall research on long-term weight change patterns and predictors of weight changes in children/adolescents following lifestyle interventions is scarce but important in order to create individualized treatment approaches. Therefore, we analyzed a large health care database of overweight/obese children/adolescents/young adults who were followed up for at least 2 years. The objectives of this study were to provide frequencies of different BMI-SDS change patterns and to identify associations between pretreatment sociodemographic characteristics and different longterm weight patterns.

\section{Methods}

\section{Study Cohort and Design}

This is a retrospective study with data drawn from the APV (Adiposity Patients Verlaufsbeobachtung) registry, a large database for quality assurance for certified in- and outpatient pediatric obesity treatment centers in Germany, Austria and Switzerland [18]. The APV software enables longitudinal documentation of anthropometric parameters, metabolic control and treatment mo- dalities. Twice a year, data are transmitted anonymously to the University of Ulm for central analysis. Central analysis was approved by the Ethics Committee of the University of Ulm, and each participating center had to comply with the ethical and data management guidelines of the local institution. To avoid bias resulting from different therapeutic settings, our study only included multiprofessional pediatric obesity centers that offered standardized multidimensional lifestyle intervention programs, comprising nutritional counseling, exercise, implementation of behavior modification and parental training according to the specifications of the Guidelines of the German Working Group of Childhood Obesity (AGA) [6].

For the purpose of this study, data from 29,181 children/adolescents/young adults ( $49.3 \%$ boys) presenting for lifestyle intervention in the years 2000-2012 to one of the 157 outpatient centers specialized in pediatric obesity were selected according to the following inclusion criteria at initial presentation: age 5-25 years and overweight or obesity/extreme obesity. Patients with appetite or weight-affecting medications or bariatric surgery, as well as patients with syndromic, drug-induced or endocrine causes of overweight/obesity were excluded from the analysis.

\section{Assessments}

Anthropometric Data

In the APV cohort, anthropometric parameters are documented routinely according to standardized AGA specifications, as described previously [18]. Weight status was assessed by BMI [body weight $(\mathrm{kg}) /$ body height $\left.(\mathrm{m})^{2}\right]$. The degree of overweight was quantified using Cole's Box-Cox transformation, expressing BMI as SDS [19], based on German-population-based reference data, as recommended by the International Task Force of Obesity [20, 21]. A cutoff $\geq 1.28$ SDS (90th percentile) was applied to classify overweight, a cutoff $\geq 1.88$ SDS (97th percentile) to classify obesity, and a cutoff $\geq 2.58$ ( 99.5 th percentile) to classify extreme obesity [6].

\section{Sociodemographic Data}

In addition to anthropometric data, the APV registry collects self-reported family sociodemographic variables, such as migration background, school type, family setting, parental employment situation, age and gender. In this study, we analyzed the association between these patient characteristics and the long-term weight change pattern. The study population was divided into the following three age categories: $5-11,12-15$ and $16-25$ years. According to Schenk et al. [22], a child/adolescent was defined as having a migration background if at least one parent immigrated from a country outside of Austria, Switzerland or Germany. School education was coded as children/adolescents attending regular schools versus children/adolescents attending schools for children with special needs, including children with learning disabilities, which is referred to as 'special school' in the following. Parental employment status was coded as at least one parent unemployed versus both parents employed. Family structure was defined as either living with only one/no parent versus two-parent families.

\section{Long-Term Weight Change Patterns}

Depending on the organizational structure of the treatment center, the interval between patient visits differed between the centers. To make time points comparable, our study time points 
Table 1. Flowchart

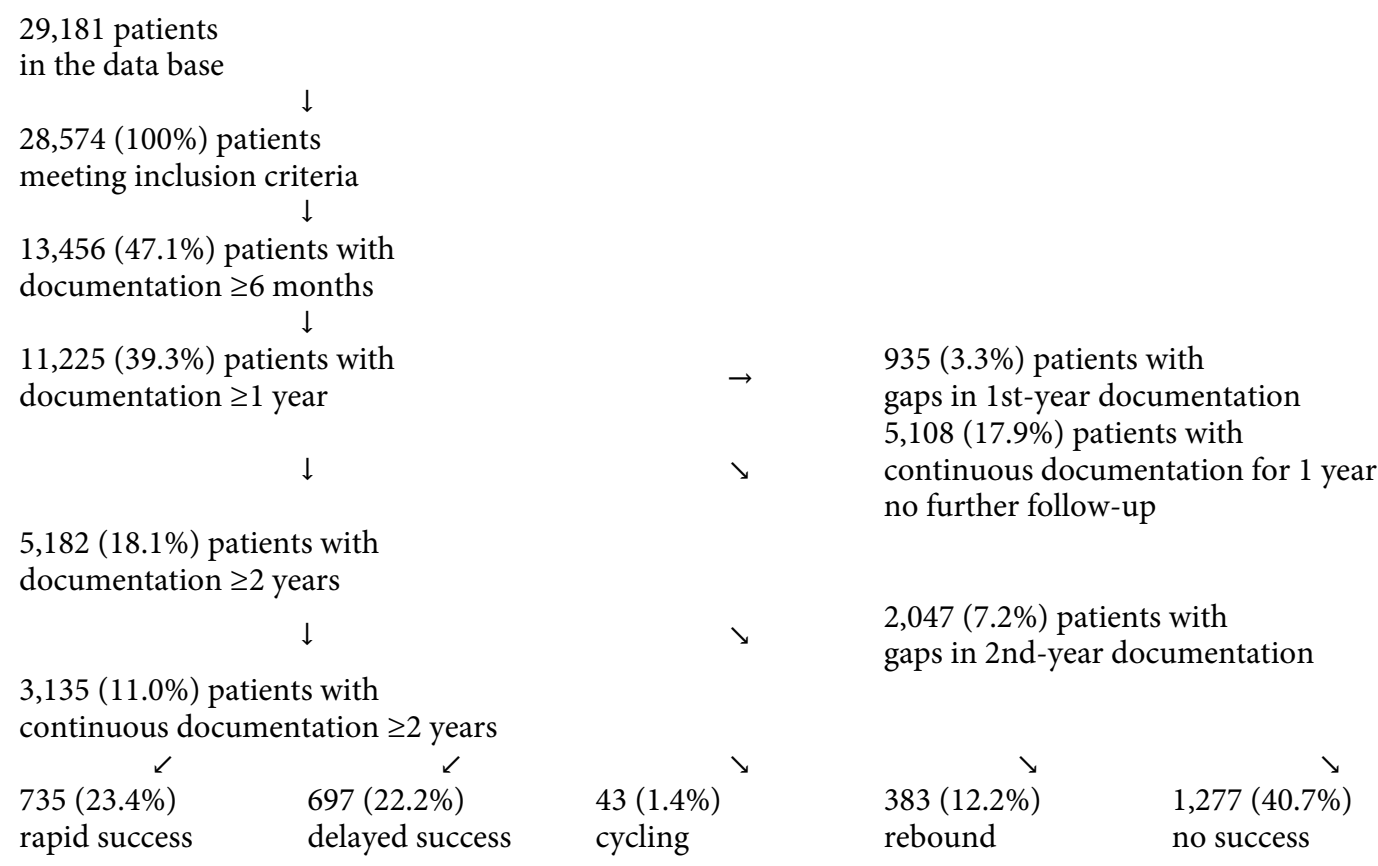

were defined as follows: 0 month (BMI obtained at the first visit, i.e. on days 0-7), 6 months after initiation of therapy (BMI obtained between 4 and 9 months), 12 months after initiation of therapy (BMI obtained between days 274 and 547) and 24 months after initiation of therapy (BMI obtained between days 548 and 912).

To examine patient weight trajectories, only patients with available BMI-SDS values at all four time points were included. When more than one BMI value was available within one of the above-outlined time intervals, the average BMI was calculated. We defined treatment success using the definition proposed by the AGA Group [18]: a reduction in BMI-SDS of at least 0.2, which corresponds to a weight reduction of $5 \%$, was used to define the success of weight reduction and maintenance in adults.

Long-term BMI-SDS changes were examined and patients were categorized into five groups: 'rapid success, weight maintenance' (reduction in BMI-SDS within 6 months of at least 0.2 and no increase in BMI-SDS above this cutoff point thereafter); 'delayed success, weight maintenance' (weight maintenance: reduction in BMI-SDS of at least 0.2 after 1 year and no increase in BMISDS above this cutoff point thereafter); 'cycling' (reduction in BMI-SDS within 6 months by at least 0.2 , increase above this cutoff point after 1 year and reduction of at least 0.2 compared to baseline after 2 years); 'initial success, rebound' (reduction in BMI-SDS within 6 months by at least 0.2 , but increase above this cutoff point after 1 year and/or 2 years) and 'no success' (neither after 6 months nor after 1 or 2 years a reduction in BMI-SDS of at least 0.2 compared to baseline).

Patients in the BMI pattern categories: 'rapid success', 'delayed success' and 'cycling' were considered to be successful.

\section{Statistical Analysis}

Statistical analyses were completed using SAS version 9.4 (SAS Institute, Cary, N.C., USA). Data are presented as means \pm SD or prevalence in percent. Statistical differences between the selected APV study population and the entire APV population were tested using the Kruskal-Wallis test for continuous variables and the $\chi^{2}$ test for categorical data. Bonferroni's test was used to correct for multiple testing. Multiple logistic regression analyses with BMI-SDS patterns as dependent variable were used to assess the impact of the following variables on BMI patterns over time: age, sex, initial BMI category, type of school, migration background, familial living situation and parental employment. Each BMI-SDS long-term pattern was compared to the pattern 'no success' as reference. Results are reported as odds ratios (OR) and $95 \%$ confidence intervals (CI). Values of $\mathrm{p}<0.05$ were regarded as statistically significant.

\section{Results}

\section{Study Cohort}

A flowchart of the patient selection process is given in table 1 . A total of 28,574 patients fulfilled the inclusion criteria; 5,182 (18.1\%) of them were followed for at least 2 years. Complete follow-up data were available for 3,135 (11.0\%) patients, i.e. data at baseline and for the 6-, 12and 24-month follow-ups, to be able to calculate longterm weight patterns. 
Table 2. Baseline data of the study population

\begin{tabular}{lccc}
\hline & $\begin{array}{l}\text { All APV } \\
\text { patients } \\
(\mathrm{n}=28,574)\end{array}$ & $\begin{array}{l}\text { Continuous follow-up for } \\
1 \text { year, no further follow-up } \\
(\mathrm{n}=5,108)\end{array}$ & $\begin{array}{l}\text { Continuous } \\
\text { follow-up for 2 years } \\
(\mathrm{n}=3,135)\end{array}$ \\
\hline Age group & & & $59.9 \%$ \\
$\quad 5-11$ years & $56.0 \%$ & $55.1 \%$ & $37.3 \%$ \\
12-15 years & $38.7 \%$ & $41.1 \%$ & $2.8 \%$ \\
16-25 years & $5.3 \%$ & $3.9 \%$ & $54.6 \%$ \\
Female & $50.7 \%$ & $53.0 \%$ & $13.1 \%$ \\
BMI category at baseline & & & $51.1 \%$ \\
$\quad$ Overweight & $14.1 \%$ & $13.8 \%$ & $35.8 \%$ \\
$\quad$ Obese & $48.7 \%$ & $51.5 \%$ & $2.42 \pm 0.51$ \\
$\quad$ Extremely obese & $37.2 \%$ & $34.7 \%$ & $47.1 \%$ \\
BMI-SDS at baseline (mean \pm SD) & $2.44 \pm 0.53$ & $2.41 \pm 0.49$ & $1.9 \%$ \\
Treatment success (BMI-SDS reduction $\geq 0.2)$ & & $41.3 \%$ & $13.2 \%$ \\
Attendance of school for children with special needs & $2.0 \%$ & $2.0 \%$ & $9.6 \%$ \\
Migration background & $12.7 \%$ & $13.6 \%$ & $5.7 \%$ \\
Living with one or no parent & $10.4 \%$ & $12.6 \%$ & $5.0 \%$ \\
At least one parent unemployed & $4.7 \%$ & & \\
\hline
\end{tabular}

Baseline data of all patients fulfilling the inclusion criteria and of those with continuous documentation over 1 and 2 years, respectively, are listed in table 2 . Patients with complete data over 2 years differed from the entire study population with regard to the age group 5-11 years (all vs. 2 -year follow-up: 56 vs. $59.9 \%$, respectively) and BMI category 'obesity' (whole sample vs. 2-year follow-up: 48.7 vs. $51.1 \%$ ). The percentage of patients with migration background was higher in patients with complete data for 1 and 2 years compared to all patients documented in the APV registry (whole sample vs. 2-year follow-up: 12.7 vs. $13.2 \%$ ). Female patients were overrepresented in the study population irrespective of the follow-up. However, due to the large cohort size and the moderate pretreatment differences between groups, we consider the analysis of the patients included to be valid.

\section{Longitudinal BMI-SDS Changes}

Altogether, $47.1 \%$ of the patients successfully maintained a weight reduction of 0.2 BMI-SDS 2 years after the initiation of treatment (table 2). The time course of weight changes over 2 years, expressed as BMI-SDS, is depicted in figure 1.

The mean decrease in BMI-SDS after 6 months was similar in patients with rapid success, initial success (later rebound) and weight cycling ( -0.46 vs. -0.25 vs. -0.3 BMI-SDS). In patients with rapid success and weight maintenance, BMI-SDS further decreased over time,

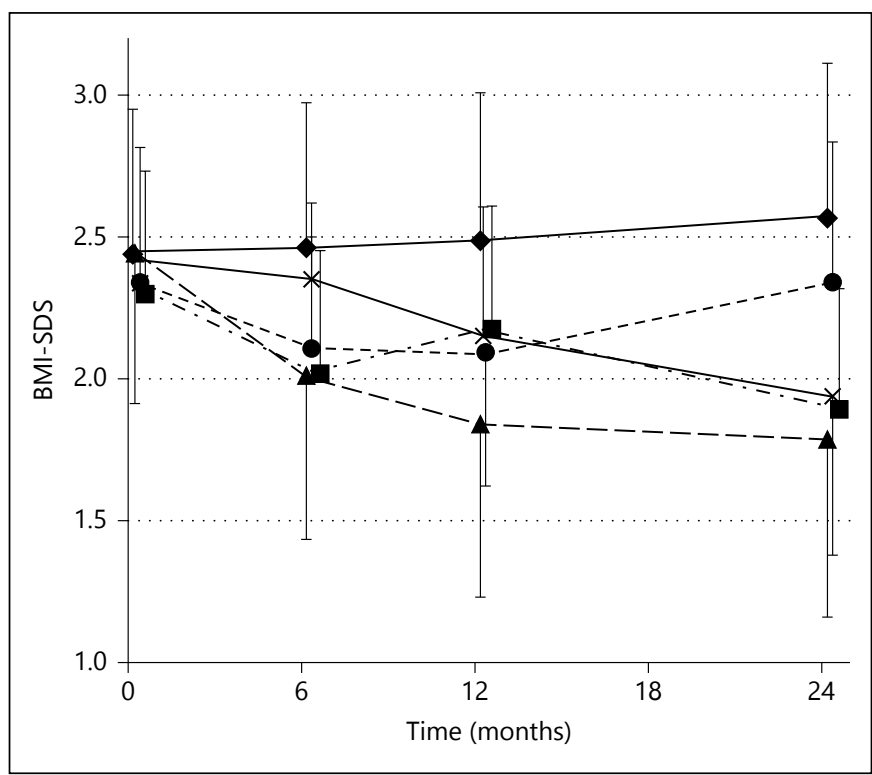

Fig. 1. Time course patterns of weight, expressed as BMI-SDS (means $\pm \mathrm{SD}$ ). $\diamond$ = No success throughout; $\bullet$ = initial success, rebound; $\boldsymbol{\Delta}$ = rapid success, weight maintenance; $\mathrm{x}=$ delayed success, weight maintenance; $\mathbf{\square}=$ cycling.

reaching the lowest mean values of all patient groups after 2 years (BMI-SDS $1.79 \pm 0.62$ ).

The other patient groups, whose weight course was also defined as success after 2 years, reached slightly higher mean BMI-SDS (delayed success: $1.92 \pm 0.57$; 
Table 3. Results of logistic regression analysis: adjusted OR (95\% CI) for different weight course patterns in patients followed up for 2 years

\begin{tabular}{|c|c|c|c|c|c|c|}
\hline & & $\begin{array}{l}\text { Rapid success/ } \\
\text { maintenance }{ }^{1} \\
(\mathrm{n}=735)\end{array}$ & $\begin{array}{l}\text { Delayed success/ } \\
\text { maintenance }{ }^{1} \\
(\mathrm{n}=697)\end{array}$ & $\begin{array}{l}\text { Cycling }^{1} \\
(\mathrm{n}=43)\end{array}$ & $\begin{array}{l}\text { Initial success/ } \\
\text { rebound }{ }^{1} \\
(\mathrm{n}=383)\end{array}$ & $\begin{array}{l}\text { Success (all) } \\
(\mathrm{n}=1,475)\end{array}$ \\
\hline \multirow[t]{2}{*}{ Age } & $12-15$ (ref. 5-11) years & $0.56(0.46-0.67)$ & $0.56(0.46-0.68)$ & $0.40(0.19-0.82)$ & $0.76(0.60-0.97)$ & $0.59(0.51-0.69)$ \\
\hline & $16-25$ (ref. 5-11) years & $0.96(0.55-1.65)$ & $0.60(0.31-1.14)$ & $1.04(0.20-5.41)$ & $1.49(0.80-2.77)$ & $0.76(0.43-1.04)$ \\
\hline Migration background & yes (ref. no) & $0.72(0.54-0.96)$ & $0.96(0.73-1.26)$ & $0.61(0.18-2.05)$ & $0.64(0.43-0.93)$ & $0.90(0.73-1.12)$ \\
\hline $\begin{array}{l}\text { School for children with } \\
\text { special needs }\end{array}$ & yes (ref. no) & $0.60(0.29-1.25)$ & $0.78(0.39-1.56)$ & n.a. & $1.14(0.53-2.46)$ & $0.67(0.39-1.15)$ \\
\hline Living with one or no parent & yes (ref. no) & $0.96(0.69-1.33)$ & $0.89(0.64-1.24)$ & $0.91(0.25-3.38)$ & $1.42(0.99-2.04)$ & $0.83(0.65-1.06)$ \\
\hline
\end{tabular}

Success (all) = Rapid success + delayed success + cycling vs. no success $=$ initial success/rebound + no success throughout $(n=1,660)$. Significant values $(\mathrm{p} \leq 0.05)$ are shown in italics.

${ }^{1}$ Compared to the no success groups $(\mathrm{n}=1,277)$.

weight cycling: $1.97 \pm 0.51$ ) values after 2 years. Patients with weight rebound showed a BMI-SDS reduction after 6 months and 1 year, which was comparable to patients with weight cycling or delayed success, but after 2 years, the mean BMI-SDS was similar to the baseline value (initial BMI-SDS vs. 2-year BMI-SDS weight rebound group: $2.37 \pm 0.51$ vs. $2.38 \pm 0.55$ ). Patients without treatment success throughout the observation period had a higher BMI-SDS value after 2 years compared to baseline (initial BMI-SDS vs. 2 -year BMI-SDS: $2.45 \pm 0.51$ vs. $2.58 \pm$ $0.54)$.

Associations between Sociodemographic Variables and BMI-SDS Change Patterns

To assess the effect of patient characteristics on longterm BMI-SDS patterns, logistic regression was performed to investigate potential predictors of long-term BMI-SDS patterns (table 3). Thus, being male appeared as a potential predictor in the BMI-SDS patterns classified as treatment success, i.e. 'rapid success and weight maintenance' [OR: 1.36 (95\% CI: 1.13-1.74)], 'delayed success and weight maintenance’ [OR: 1.45 (95\% CI: 1.2-1.75)] and 'cycling' [OR: 2.08 (95\% CI: 1.1-3.96)]. In addition, the results demonstrated $44-60 \%$ lower odds of having a successful long-term BMI pattern for adolescents in the group aged 12-15 years compared to children aged 5-11 years. Similar results where found when all patients with successful BMI-SDS patterns ('rapid success', 'delayed success' and 'cycling') were combined in one group and compared to those with no weight reduction after 2 years ('no success' or 'rebound'). Here, boys showed higher odds for treatment success [OR: 1.38 (95\% CI: 1.2-1.59)]. Patients in the age group of 12-15 years had lower odds for successful weight reduction and maintenance compared to patients in the age group of 5-11 years [OR: 0.59 (95\% CI: 0.51-0.69)].

Patients with extreme obesity showed lower odds for initial treatment success with consecutive weight rebound' [OR: 0.69 (95\% CI: 0.48-0.99)] compared to overweight patients. Patients with a migration background had lower odds of 'rapid success' [OR: 0.72 (95\% CI: 0.54$0.96)$ ] and of 'weight rebound' [OR: 0.64 (95\% CI: 0.43$0.93)$ ] compared to nonmigrant patients.

No significant associations between weight course patterns and the variables type of school, family structure and parental employment status were observed.

\section{Discussion}

To our knowledge, this study was the first large-scale study in Germany to provide frequencies of different longitudinal weight change patterns and to identify associations between patient characteristics and BMI-SDS 
change patterns 2 years after the initiation of a weight loss intervention in overweight/obese children/adolescents/ young adults.

Despite improvements in weight loss treatment efficacy, weight maintenance after weight loss remains a major challenge [23], as many obese patients regain weight after treatment $[12,24]$. Research has previously tried to identify long-term weight patterns for obese pediatric [25] and adult [26] patients. In our study sample, patients with delayed treatment success and patients with weight cycling met the criterion for successful weight reduction only 2 years after treatment initiation. This underlines the importance of long-term treatment strategies. Many of the adult obese patients have a history of repeated attempts to reduce weight. In many cases, an initial weight loss of $5-10 \%$ is followed by a greater weight regain [27], resulting in repeated weight cycling. There is evidence that weight cycling is associated with increased mortality in adults [28]. In our patients, only a small number of patients experienced weight cycling $(1.4 \%)$ within the 2 -year observation period. However, recent study results indicate a shift of the onset of a pattern of weight cycling from adulthood towards youth [29].

With regard to potential predictors of long-term weight changes in our study population, four patient characteristics were associated with at least one BMI-SDS change pattern.

The following significant effects could be identified: First, the BMI-SDS changes over time were not independent of sex. Boys were more successful in long-term BMI-SDS reduction compared to girls. Previous studies on predictors of long-term changes in BMI after lifestyle intervention did not find sex differences $[15,17]$. Second, adolescence (age group 12-15 years) was associated with low treatment success compared to children aged 5-11 years. This finding is consistent with a previous study that showed that the highest decrease in BMI-SDS over 5 years was achieved among the youngest children [25]. This underlines the importance of early interventions in order to treat overweight before puberty. Nevertheless, adolescence is a critical period with regard to obesity prevention and treatment, as it is during that stage of life that behaviors such as dietary patterns and levels of physical activity are largely formed [30]. Third, our findings regarding associations between migration background and successful treatment were inconsistent, as patients with migration background had both lower odds for rapid success followed by weight maintenance and for initial success followed by rebound. Studies have

Weight Loss Maintenance in Pediatric Patients reported that children with a migration background living in Germany have a higher risk of obesity/overweight $[1,31]$ and metabolic comorbidities [32], and lower treatment success rates compared to their native counterparts [33].

Conflicting data exist on the natural course of weight development throughout childhood and adolescence. In a large longitudinal cohort study on more than 5,000 children, $34 \%$ of overweight children became obese between 7 and 13 years of age [34]. In a multiethnic school cohort (10-12 years of age), the overall prevalence of overweight/ obesity remained stable over a period of 28 months due to almost equal incidence and remission rates. However, the BMI of African-American girls increased while it decreased in African-American boys [32].

Further studies should be performed to improve indepth understanding of different long-term weight patterns and its determinants in order to develop more individualized treatment strategies that are sensitive to patients' needs.

\section{Methodological Discussion}

The main strengths of our analysis are the large sample size and the wide age range. Possible limitations of our study include the following: First, our study sample is highly selected (treatment-seeking patients and exclusion of severely overweight patients and patients lost to follow-up), thus limiting the generalizability of our results. As often seen in routine anti-obesity treatment, there was only a small percentage of patients who had complete long-term follow-up (2 years) data available (11.0\%). We are aware that analyses restricted to participants who completed the study are problematic as they ignore dropouts who exhibit the greatest barriers to success. Second, the routine documentation used for the analyses comprised only a limited number of possible prognosticators, thus lacking information on other psychosocial parameters that may be predictive of treatment success. Recently, Fröhlich et al. [35] identified maternal depression and avoidance of closeness, older age, and one or more obese siblings as risks for failure during weight reduction therapy. Third, we did not adjust our analysis for treatment center, which could constitute a confounding factor. However, in a study on BMI patterns over 5 years in obese children, the treatment center was not a predictor for long-term treatment success [15]. Our study only included multiprofessional pediatric obesity centers that offered standardized multidimensional lifestyle intervention programs according to the specifications of the AGA Guidelines. Fourth, a 
follow-up for a longer period than 2 years after treatment initiation would be desirable. The time period of 2 years might not be long enough to detect meaningful weight course patterns. For example, we can only speculate if successful weight reducers in the youngest age group will be able to maintain their weight during puberty. Fifth, BMI-SDS was used as an outcome parameter. Although BMI is a good instrument to measure overweight, it has its limitations. For instance, an increase in muscle mass can lead to an increase of BMI [36]. Sixth, we did not measure the impact of weight loss maintenance on health-related outcomes. Although changes in BMI-SDS have shown to be associated with a decreased cardiovascular risk, further research is needed to analyze the relative weight change necessary for long-term physical benefits among youth.

\section{Conclusion}

Using health care data in overweight/obese children/adolescents/young adults, we were able to determine frequencies of different long-term BMI patterns and to identify pretreatment characteristics that potentially predict treatment success and weight loss maintenance for a period of 2 years. Younger and male patients were more likely to reduce weight and maintain weight loss, whereas patients with migration background were less successful in rapid weight reduction. New obesity treatment concepts are warranted to improve long-term efficacy, especially among vulnerable patient groups. Moreover, current treatment concepts have to be reviewed as to their suitability for female/ pubertal patients. (Competence Network for Obesity), funded by the Federal Ministry of Education and Research (FKZ 01GI1130) and the German Federal Center for Health Education (BZgA). first version of the analyses in SAS; Carsten Meyerhoff, University of Ulm, and Luise Martin, Charité Universitätsmedizin Berlin, who helped to prepare the paper, as well as to Anna Anastassiades Group taking care of overweight children, contributing to the APV database and thus enabling these analyses:

- Pediatric clinics in Augsburg, Bad Hersfeld, Bad Kreuznach, Berlin, Bremen, Darmstadt, Datteln, Detmold, Dinslaken, Dorsten, Erlangen, Ettenheim, Frankfurt, Freiburg, Fürth, Gotha, Göttingen, Hagen, Hamburg, Hannover, Herdecke, Homburg, Kiel, Köln, Leipzig, Lingen, Lübeck, Madgeburg, Mönchengladbach, Neunkirchen, Neuss, Oberhausen, Osnabrück, Passau, Pocking, Ravensburg, Saalfeld, Salzgitter, Siegen, St. Augustin, Tübingen, Ulm, Viersen and Wiesbaden (Germany); Bregenz, Dornbirn, Feldkirch, Salzburg, St. Pölten and Wien (Austria), and St. Gallen (Switzerland).

- Pediatric rehabilitation units in Amrum, Bad Bodenteich, Bad Frankenhausen, Bad Kösen, Bad Orb, Bad Rothenfelde, Bad Salzungen, Berchtesgaden, Bischofswiesen, Bruchweiler, Feldberg, Gaissach, Garz, Köln, Kölpinsee, Kreischa, Murnau, Norden, OyMittelberg, Scheidegg, Seebad Heringsdorf, Simonswald, Wangen, Westerland, Wustrow and Wyk (Germany).

- Pediatricians in private practice in Bad Neuenahr, Berlin, Böblingen, Düren, Eppingen, Freiburg, Gauting, Hagen, Hamburg, Kassel, Münster, Niederkassel, Nürnberg, Rendsburg, Straubing, Villingen-Schwennigen and Waldbröl (Germany) and Giffers (Switzerland).

- Nutritional councellors in Bad Fallingbostel, Bad Segeberg, Bensheim, Berlin, Blaubeuren, Braunschweig, Brügge, Buchholz, Bühl, Dieburg, Dresden, Düsseldorf, Eschede, Flensburg, Friedrichsdorf, Gittelde, Göttingen, Gröbenzell, Hamburg, Haßfurt, Herne, Hirschberg, Homburg, Köln, Korbach, Leipzig, Lindau, Lindenberg, Luhe, Mahlow, Menden, Mühlhausen, München, Munster, Nagold, Neumünster, Nürnberg, Oberhausen, Oberstaufen, Oldenburg, Oldendorf, Overath, Paderborn, Pforzheim, Pönitz, Poppenricht, Potsdam, Ravensburg, Reiskirchen, Ronneburg, Rosenheim, Rottweil, Rüsselsheim, Saarbrücken, Schliengen, Senden, Siegburg, Siegburg, Solingen, Sonneberg, Tholey, Untergruppenbach, Waltrop, Wiesmoor, Windach, Würzburg, Zorneding and Zwickau.

\section{Disclosure Statement}

The authors declare no conflict of interest.

\section{Acknowledgments}

This work was supported by the 'Kompetenznetz Adipositas'

The authors are grateful to Alexander Hose, who prepared the (Ernährung + Diät, Ravensburg, Germany) and Martin de Souza (Department of Epidemiology, University of Ulm, Germany), who supported data management.

We are indebted to all health professionals of the APV Study

References
Horm Res Paediatr 2014;82:380-387 DOI: $10.1159 / 000368963$
1 Kurth B-M, Schaffrath Rosario A: The prevalence of overweight and obese children and adolescents living in Germany. Results of the German Health Interview and Examination Survey for Children and Adolescents (KiGGS) (in German). Bundesgesundheitsblatt Gesundheitsforschung Gesundheitsschutz 2007; 50:736-743.

$\checkmark 2$ Visscher TL, Seidell JC: The public health impact of obesity. Annu Rev Public Health 2001; 22:355-375.

- 3 Dietz WH, Robinson TN: Clinical practice. Overweight children and adolescents. N Engl J Med 2005;352:2100-2109.

4 Freedman DS, Khan LK, Serdula MK, Dietz WH, Srinivasan SR, Berenson GS: The relation of childhood BMI to adult adiposity: the Bogalusa Heart Study. Pediatrics 2005;115: $22-27$. 
5 Juonala M, Magnussen CG, Berenson GS, 16 Reinehr T, Widhalm K, l' Allemand D, WieVenn A, Burns TL, Sabin MA, Srinivasan SR, Daniels SR, Davis PH, Chen W, Sun C, Cheung M, Viikari JSA, Dwyer T, Raitakari OT: Childhood adiposity, adult adiposity, and cardiovascular risk factors. N Engl J Med 2011;365:1876-1885.

6 Guidelines of the German Working Group of $>_{1}$ Childhood Obesity (in German). www.a-g-a. de.

7 Kirschenbaum DS, Gierut KJ: Five recent expert recommendations on the treatment of childhood and adolescent obesity: toward an emerging consensus - a stepped care approach. Child Obes 2013;9:376-385.

$>8$ Ho M, Garnett SP, Baur L, Burrows T, Stewart L, Neve M, Collins C: Effectiveness of lifestyle interventions in child obesity: systematic review with meta-analysis. Pediatrics 2012; 130:e1647-e1671.

$\checkmark 9$ Atlantis E, Barnes EH, Singh MAF: Efficacy of exercise for treating overweight in children and adolescents: a systematic review. Int J Obes (Lond) 2006;30:1027-1040.

$>10$ Ho M, Garnett SP, Baur LA, Burrows T, Stewart L, Neve M, Collins C: Impact of dietary and exercise interventions on weight change and metabolic outcomes in obese children and adolescents: a systematic review and meta-analysis of randomized trials. JAMA Pediatr 2013;167:759-768.

$>11$ Ross R: The challenge of obesity treatment: avoiding weight regain. CMAJ 2009;180:997998.

$>12$ Svetkey LP, Stevens VJ, Brantley PJ, Appel LJ, Hollis JF, Loria CM, Vollmer WM, Gullion CM, Funk K, Smith P, Samuel-Hodge C, Myers V, Lien LF, Laferriere D, Kennedy B, Jerome GJ, Heinith F, Harsha DW, Evans P, Erlinger TP, Dalcin AT, Coughlin J, Charleston J, Champagne CM, Bauck A, Ard JD, Aicher K; Weight Loss Maintenance Collaborative Research Group: Comparison of strategies for sustaining weight loss: the weight loss maintenance randomized controlled trial. JAMA 2008;299:1139-1148.

$>13$ Wilfley DE, Stein RI, Saelens BE, Mockus DS, Matt GE, Hayden-Wade HA, Welch RR, Schechtman KB, Thompson PA, Epstein LH: Efficacy of maintenance treatment approaches for childhood overweight: a randomized controlled trial. JAMA 2007;298:1661-1673.

$>14$ Crujeiras AB, Goyenechea E, Abete I, Lage M, Carreira MC, Martínez JA, Casanueva FF: Weight regain after a diet-induced loss is predicted by higher baseline leptin and lower ghrelin plasma levels. J Clin Endocrinol Metab 2010;95:5037-5044.

15 Reinehr T, Kleber M, Lass N, Toschke AM: Body mass index patterns over $5 \mathrm{y}$ in obese children motivated to participate in a 1-y lifestyle intervention: age as a predictor of longterm success. Am J Clin Nutr 2010;91:11651171. gand S, Wabitsch M, Holl RW; APV-Wiss STudy Group and German Competence Net Obesity: Two-year follow-up in 21,784 overweight children and adolescents with lifestyle intervention. Obesity (Silver Spring) 2009;17: 1196-1199.

17 Fröhlich G, Pott W, Albayrak Ö, Hebebrand J, Pauli-Pott U: Conditions of long-term success in a lifestyle intervention for overweight and obese youths. Pediatrics 2011;128:e779e785.

18 Reinehr T, Wabitsch M, Andler W, Beyer P, Böttner A, Chen-Stute A, Fromme C, Hampel O, Keller KM, Kilian U, Kolbe H, Lob-Corzilius T, Marg W, Mayer H, Mohnike K, Oepen J, Povel C, Richter B, Riedinger N, Schauerte G, Schmahlfeldt G, Siegfried W, Smuda P, Stachow R, van Egmond-Fröhlich A, Weiten J, Wiegand S, Witte S, Zindel V, Holl RW; APV Study Group: Medical care of obese children and adolescents. APV: a standardised multicentre documentation derived to study initial presentation and cardiovascular risk factors in patients transferred to specialised treatment institutions. Eur J Pediatr 2004;163: 308-312.

19 Yanovski JA, Yanovski SZ: Treatment of pediatric and adolescent obesity. JAMA 2003; 289:1851-1853.

20 Cole TJ, Bellizzi MC, Flegal KM, Dietz WH: Establishing a standard definition for child overweight and obesity worldwide: international survey. BMJ 2000;320:1240-1243.

21 Kromeyer-Hauschild K, Wabitsch M, Kunze D, Geller F, Geiss HC, Hesse V, von Hippel A, Jaeger U, Johnsen D, Korte W, Menner K, Müller G, Müller JM, Niemann-Pilatus A, Remer T, Schaefer F, Wittchen H-U, Zabransky S, Zellner K, Ziegler A, Hebebrand J: Percentiles of body mass index in children and adolescents evaluated from different regional German studies (in German). Monatsschr Kinderheilkd 2001;149:807-818.

22 Schenk L, Ellert U, Neuhauser H: Children and adolescents in Germany with a migration background. Methodical aspects in the German Health Interview and Examination Survey for Children and Adolescents (KiGGS) (in German). Bundesgesundheitsblatt Gesundheitsforschung Gesundheitsschutz 2007; 50:590-599.

23 Oude Luttikhuis H, Baur L, Jansen H, Shrewsbury VA, O'Malley C, Stolk RP, Summerbell $\mathrm{CD}$ : Interventions for treating obesity in children. Cochrane Database Syst Rev 2009; 1:CD001872.

24 Wilfley DE, Stein RI, Saelens BE, Mockus DS, Matt GE, Hayden-Wade HA, Welch RR, Schechtman KB, Thompson PA, Epstein LH: Efficacy of maintenance treatment approaches for childhood overweight: a randomized controlled trial. JAMA 2007;298:1661-1673.
25 Reinehr T, Kleber M, Lass N, Toschke AM: Body mass index patterns over $5 \mathrm{y}$ in obese children motivated to participate in a 1-y lifestyle intervention: age as a predictor of longterm success. Am J Clin Nutr 2010;91:11651171.

-26 Neiberg RH, Wing RR, Bray GA, Reboussin DM, Rickman AD, Johnson KC, Kitabchi AE, Faulconbridge LF, Kitzman DW, Espeland MA; Look AHEAD Research Group: Patterns of weight change associated with long-term weight change and cardiovascular disease risk factors in the Look AHEAD Study. Obesity (Silver Spring) 2012;20:2048-2056.

27 Mann T, Tomiyama AJ, Westling E, Lew A-M, Samuels B, Chatman J: Medicare's search for effective obesity treatments: diets are not the answer. Am Psychol 2007;62:220 233.

28 Lissner L, Odell PM, D’Agostino RB, Stokes J 3rd, Kreger BE, Belanger AJ, Brownell KD: Variability of body weight and health outcomes in the Framingham population. N Engl J Med 1991;324:1839-1844.

29 Montani J-P, Viecelli AK, Prévot A, Dulloo AG: Weight cycling during growth and beyond as a risk factor for later cardiovascular diseases: the 'repeated overshoot' theory. Int J Obes 2005 2006;30(suppl 4):S58-S66.

30 Kuh D, Shlomo YB: A Life Course Approach to Chronic Disease Epidemiology. Oxford, Oxford University Press, 2004.

-31 Will B, Zeeb H, Baune BT: Overweight and obesity at school entry among migrant and German children: a cross-sectional study. BMC Public Health 2005;5:45.

32 Williamson DA, Han H, Johnson WD, Stewart TM, Harsha DW: Longitudinal study of body weight changes in children: who is gaining and who is losing weight. Obesity (Silver Spring) 2011;19:667-670.

33 Röbl M, de Souza M, Schiel R, Gelhaus I, Zwiauer K, Holl R, Wiegand S: The key role of psychosocial risk on therapeutic outcome in obese children and adolescents. results from a longitudinal multicenter study. Obes Facts 2013;6:297-305.

34 Reilly JJ, Bonataki M, Leary SD, Wells JC, Davey-Smith G, Emmett P, Steer C, Ness AR, Sherriff A: Progression from childhood overweight to adolescent obesity in a large contemporary cohort. Int J Pediatr Obes 2011; 6:e138-e143.

35 Fröhlich G, Pott W, Albayrak Ö, Hebebrand J, Pauli-Pott U: Conditions of long-term success in a lifestyle intervention for overweight and obese youths. Pediatrics 2011;128:e779e785.

36 Gutin B, Yin Z, Johnson M, Barbeau P: Preliminary findings of the effect of a 3-year after-school physical activity intervention on fitness and body fat: the Medical College of Georgia Fitkid Project. Int J Pediatr Obes 2008;3(suppl 1):3-9. 